\title{
Relationship Between Food Insecurity, Social Support, and Vegetable Intake Among Resettled African Refugees in Queensland, Australia
}

\author{
Catherine Gichunge, Neil Harris, Sarah Tubei, Shawn Somerset \& Patricia \\ Lee
}

To cite this article: Catherine Gichunge, Neil Harris, Sarah Tubei, Shawn Somerset \& Patricia Lee (2015) Relationship Between Food Insecurity, Social Support, and Vegetable Intake Among Resettled African Refugees in Queensland, Australia, Journal of Hunger \& Environmental Nutrition, 10:3, 379-389, DOI: 10.1080/19320248.2014.929544

To link to this article: http://dx.doi.org/10.1080/19320248.2014.929544

\section{巴nublished online: 01 Jul 2015.}

Submit your article to this journal ¿

Llll Article views: 403

Q View related articles $\longleftarrow$

View Crossmark data ¿

Citing articles: 1 View citing articles $\sqsubset$ 


\title{
Relationship Between Food Insecurity, Social Support, and Vegetable Intake Among Resettled African Refugees in Queensland, Australia
}

\author{
CATHERINE GICHUNGE, ${ }^{1}$ NEIL HARRIS, ${ }^{2}$ SARAH TUBEI, ${ }^{2}$ \\ SHAWN SOMERSET, ${ }^{3}$ and PATRICIA LEE ${ }^{2}$ \\ ${ }^{1}$ School of Business, Karatina University, Karatina, Kenya \\ ${ }^{2}$ School of Public Health, Griffith Health Institute, Griffith University, Gold Coast Campus, \\ Southport, Queensland, Australia \\ ${ }^{3}$ School of Allied and Public Health, Australian Catholic University, Public Health, Banyo, \\ Queensland, Australia
}

\begin{abstract}
The objective of this cross-sectional study was to assess the interaction of food insecurity, social support, and vegetable intake among resettled Burundian, Congolese, and Rwandan African refugees in Australia. A total of 71 bousebold food preparers were recruited through purposive sampling. Eighteen percent of the participants experienced food insecurity. Participants with low education and no social support were 5 and 4 times more likely to be food insecure, respectively. There were no significant differences in vegetable intake. Results indicate that food insecurity is more prevalent among postresettlement African refugees compared to the general Australian population and is associated with social support and education. Strategies to enhance education and social support networks for resettled African refugees may work toward alleviating food insecurity among this group.
\end{abstract}

KEYWORDS food insecurity, African refugees, social support, vegetable intake

\section{INTRODUCTION}

Though attention is often directed toward food security in the least industrialized nations, food insecurity represents a global public health issue. Food

Address correspondence to Catherine Gichunge, School of Business, Karatina University, PO Box 1957-10101, Karatina, Kenya. E-mail: cngichunge@gmail.com 
and nutrition insecurity occurs when there is insufficient access to nutritious food to meet dietary needs and food preferences and lack of environmental support for a healthy and active life. ${ }^{1}$ The prevalence of food insecurity varies among industrialized countries. Immigrants, asylum seekers, and resettled refugees living in these countries are at a higher risk of food insecurity than the native population. ${ }^{2-5}$ Poverty, unemployment, low income, and low education have contributed to the high prevalence of food insecurity among these groups. ${ }^{2,6}$ Late welfare payments, ${ }^{2}$ sending money home to assist those who remain in the country of origin, ${ }^{2,6}$ as well as costs incurred in sponsoring other family members to join the $\mathrm{m}^{7}$ also contribute to food insecurity among refugee households. Financial obligations between families undertaking resettlement and those remaining in the country of origin compete with food, household, and education expenses, further increasing the risk of food insecurity in refugee households.

Food insecure households have been found to have poor diet quality as food insecurity is linked to unhealthy diets. ${ }^{8,9}$ Food insecure resettled African refugees in the United States have been found to have a low intake of fruits and vegetables but high intake of meats and eggs. ${ }^{10}$ This increased consumption of foods such as meat and eggs may be as a result of the high status ascribed to these foods by refugee families. ${ }^{11}$ In addition, resettled refugees have reported that the price of vegetables is higher and that of meat is lower, ${ }^{12}$ which may increase the consumption of these foods, especially in households with limited finances. Furthermore, healthy nutrient-dense foods are more expensive than energy-dense foods, ${ }^{13,14}$ which may hinder households with limited income from consuming a healthy diet.

One way of coping with food insecurity is by seeking assistance from one's social support networks. ${ }^{15}$ Shumaker and Brownell ${ }^{16(\mathrm{p} 13)}$ refer to social support as "an exchange of resources between two individuals perceived by the provider or the recipient to be intended to enhance the well-being of the recipient." These resources may be emotional, instrumental, informational or companionship. ${ }^{17}$ Lack of social support has been identified as a risk factor for poor nutritional status and food insufficiency and insecurity. ${ }^{18,19}$ Social support has been reported to play a key role in refugee resettlement, especially for new arrivals, because it buffers them from isolation, stress, anxiety, and depression. ${ }^{20}$ Resettled refugees who are forced out of their homes experience a breakdown of their social support structures. Upon arrival to their new host country, refugees are often without members of their family and social support networks. ${ }^{21}$ Thus, social ties established in their new country of residence may be important in reducing the risk of food insecurity.

Although food insecurity has been documented among refugees in Australia, little is known about the relationships between food security, social support, and vegetable intake among this population. This study was conducted to assess the interaction between food insecurity, social support, and vegetable intake among resettled African refugees. The major study 
objectives were to examine the prevalence of food insecurity; identify the predictors of food insecurity; and assess the relationship between food security, social support, and vegetable intake.

\section{METHODS}

Data for this cross-sectional study were collected from 71 households of refugees from Burundi, Rwanda, and the Democratic Republic of Congo residing in South East Queensland (SEQ). This group was selected because they are from neighboring countries in the Africa Great Lakes region, and when they experienced civil wars in their countries, a majority of them sought refuge in Burundi, Rwanda, Uganda, Tanzania, and the Democratic Republic of Congo. They also speak the Swahili language, which was one of the interview languages. Participants were recruited through purposive and snowball sampling. Refugees are considered a difficult-to-reach population, ${ }^{22}$ therefore, a range of agencies were used for recruitment to maximize diversity of participation, as well as reduce sample selection bias. To be eligible for this study the household had to have a child under 18 years of age and the primary food preparer had to either speak English or Swahili. This study was conducted between April and December 2012, and data were collected using a researcher administered questionnaire. Each participant received a AU\$25 local supermarket grocery voucher as a token of appreciation for their time and participation. This study was approved by the University Human Research Ethics Committee, Griffith University.

\section{Measures}

Demographic characteristics including age, annual household income, marital status, number of children, number of people in household, employment status, years lived in Australia, English proficiency, and level of education were collected. Level of education was dichotomized as high (high school education, vocational education, college or university education) and low (no education and primary education).

The US Department of Agriculture's 18-item Household Food Security Module (HFSM) was used to measure food security. ${ }^{23}$ This instrument captures experiences related to food insecurity in the 6 months preceding completion of the module. The questions address 4 different aspects: anxiety that the household budget or food available was insufficient; perception that the foods consumed by the household members were inadequate; reports of reduced food intake and the effects of the reduced food intake for adults; and reports of reduced food intake and the effect of reduced food intake for children. The HFSM is a widely used and validated instrument that enables the participating household to be assessed as either food secure or insecure, 
with further categorization as adult food secure or insecure, and child food secure or insecure. ${ }^{23}$ The HFSM has been used among immigrant and refugee populations ${ }^{3,24}$ and has also been validated to reflect household food insecurity in various settings. ${ }^{25}$ The English and Swahili versions of this scale were checked to ensure that they had face validity. Potential participants were shown the questionnaires to ensure that the questions were not confusing and that operational definitions used were well understood.

Vegetable intake was determined using a food frequency questionnaire (FFQ). Intake frequencies were converted to daily frequencies using the following weightings (never $=0.0$; less than once per month $=0.01 ; 1-3$ times per month $=0.07$; once per week $=0.14 ; 2-3$ times per week $=0.36$; $4-5$ times per week $=0.64 ; 6$ times per week $=0.086$; once per day $=1$; and more than once per day $=2$ ). Portion sizes for each food item were determined using standard household measures guide provided to each participant. The daily servings for each item on the FFQ were calculated by multiplying the reported portion size and intake of each food item. To assess social support, participants were asked whether they have people they can depend on when in need. The responses were dichotomized as "yes" and "no."

\section{Data Analysis}

Frequencies were calculated for all variables, and chi-square test was used to examine associations between food security, social support, and demographic characteristics. The independent sample $t$ test was used to explore mean differences between household food insecurity and adult food insecurity categories and vegetable intake, and the Mann-Whitney test was used to explore mean rank differences between the child food insecurity category and vegetable intake. Logistic regression was used to determine association of demographic characteristics, social support, and food security. Data analysis was conducted using the Statistical Package for the Social Sciences version 20 (IBM, New York). A value of $P<.05$ was used to determine statistical significance.

\section{RESULTS}

One primary food preparer from each of the 71 households participated in the study. The 71 households included 383 household members $(M=5.39$, $\mathrm{SD} \pm 2.23)$ of which $255(67 \%)$ were children aged 18 years and below. Sixtythree (88.7\%) were female, and 53 (74.6\%), 9 (12.7\%) and $9(12.7 \%)$ were from Burundi, the Democratic Republic of Congo, and Rwanda, respectively. The mean age of the participants was 34.0 years $(S D \pm 8.5)$. Participants had 
lived in Australia for an average of $4.9(\mathrm{SD} \pm 1.7)$ years. Two thirds of the participants were unemployed ( $n=48,67 \%$ ), and almost half had low education ( $n=34,48 \%$ ). Of those who had low education, 24 (75\%) were unemployed, 29 (85\%) were female, and 31 (92\%) had low English proficiency. Forty-seven (66\%) of those surveyed had an annual household income below $\$ 30000$. A summary of the participants' characteristics is presented in Table 1.

Thirteen (18\%) of the primary food preparers reported they that had experienced food insecurity in the 6 months preceding the study. Socioeconomic characteristics according to food security status are outlined in Table 1 . In bivariate analyses, only education $(P=.020)$ was significantly associated with food security. Social support was marginally associated with food security $(P=.088)$. Adult food insecurity was experienced in $25(35 \%)$ households, and child food insecurity was experienced in 7 (10\%) households (Table 2). Eighteen (25.4\%) households reported that adults reduced the size of their meals, and 10 (14.1\%) households reported a reduction in the size of their children's meals, as well as the child/children having skipped a meal.

The logistic regression model containing demographic and social support variables explained $28.7 \%$ (Nagelkerke's $R^{2}$ ) of the variance of food

TABLE 1 Participant socioeconomic characteristics by food security status

\begin{tabular}{|c|c|c|c|}
\hline \multirow[b]{2}{*}{ Variable } & \multicolumn{2}{|c|}{ Food security } & \multirow[b]{2}{*}{$P$ value* } \\
\hline & Food secure $n(\%)$ & Food insecure $n(\%)$ & \\
\hline Education & & & .020 \\
\hline $\begin{array}{l}\text { Primary school education and } \\
\text { below }\end{array}$ & $24(70.6)$ & $10(29.4)$ & \\
\hline High school education and above & $34(91.9)$ & $3(8.1)$ & \\
\hline Marital status & & & .273 \\
\hline Not married & $19(76)$ & $6(24)$ & \\
\hline Married & $39(84.8)$ & $7(15.2)$ & \\
\hline Employment status & & & .273 \\
\hline Unemployed & $41(85.4)$ & $7(14.6)$ & \\
\hline Employed & $16(76.2)$ & $5(23.8)$ & \\
\hline Annual household income & & & .290 \\
\hline$\$ 20000$ and below & $16(80)$ & $4(20)$ & \\
\hline$\$ 20001-\$ 30000$ & $20(74.1)$ & $7(25.9)$ & \\
\hline$\$ 30001$ and above & $21(91.3)$ & $2(8.7)$ & \\
\hline Years lived in Australia & & & .155 \\
\hline Less than 5 years & $20(90.9)$ & $2(9.1)$ & \\
\hline 5 Years or more & $38(77.6)$ & $11(22.4)$ & \\
\hline Able to speak English well & & & .300 \\
\hline No & $31(77.5)$ & $9(22.5)$ & \\
\hline Yes & $27(87.1)$ & $4(12.9)$ & \\
\hline Has people to depend on & & & .088 \\
\hline No & $17(70.8)$ & $7(29.2)$ & \\
\hline Yes & $41(87.2)$ & $6(12.8)$ & \\
\hline
\end{tabular}

${ }^{*}$ Chi-square test. 
TABLE 2 Prevalence of adult and child household food insecurity

\begin{tabular}{lc}
\hline Variable & $n(\%)$ \\
\hline Adult food insecurity & \\
High food security among adults & $46(64.8)$ \\
Food insecurity among adults & $25(35.2)$ \\
Child food insecurity & $64(90.1)$ \\
High or marginal food security among children & $7(9.9)$ \\
Low food security among children & \\
\hline
\end{tabular}

TABLE 3 Predictors of food insecurity (OR and its 95\% CI)

\begin{tabular}{llll}
\hline Variable & OR & $95 \%$ CI & $P$ value \\
\hline Education level & & & \\
$\quad$ Primary school education and below & 4.7 & $1.0-28.72$ & .049 \\
$\quad$ High school education and above (ref) & 1.00 & & \\
Employment status & & & .129 \\
$\quad$ Unemployed & 0.29 & $0.06-1.43$ & \\
$\quad$ Employed (ref) & 1.00 & & .306 \\
Annual household income & & & .571 \\
$\quad \$ 20$ 001-30 000 & 2.5 & $0.43-14.37$ & \\
$\quad$ \$30 000 & 0.55 & $0.07-4.3$ & .049 \\
$\quad<20000$ (ref) & & & \\
Has people to depend on & 4.4 & $1.01-18.81$ & \\
$\quad$ No & 1.00 & & \\
$\quad$ Yes (ref) & & & \\
\hline
\end{tabular}

OR indicates odds ratio; CI, confidence interval; ref, reference category.

insecurity, and $85.3 \%$ of cases were correctly classified. Participant's education level $(P=.049)$ and availability of social support $(P=.049)$ were significant predictors of food insecurity. Compared to those with a high education level, participants with a low education level were 4.7 times more likely to be food insecure. Individuals who did not have social supportthat is, someone to depend on when in need-were 4.4 times more likely to be food insecure compared to those with social support (Table 3). No significant associations were found between vegetable intake and food security status.

\section{DISCUSSION}

The high level of reported food insecurity in this sample is consistent with findings from other studies conducted among African refugees resettled in industrialized countries. ${ }^{2,3,6}$ However, this prevalence (18\%) is considerably lower than that previously reported (71\%) among refugees in Australia. ${ }^{2}$ It should be noted, however, that participants in the Australian study by Gallegos and colleagues ${ }^{2}$ were accessing a torture and trauma service, which 
may have contributed to this increased prevalence. Furthermore, the difference may be attributed to the food security measurement that was used in the 2 studies. The HFSM was chosen over the Australian single- and 2-item food security tools because it is more comprehensive and provides information on severity levels of household food insecurity. A 16-item version of the HFSM tool used in this study is more sensitive than the Australian single-item measurement. ${ }^{26}$ Another Australian study reported a food insecurity prevalence of $25 \%$ using the 18 -item HFSM. ${ }^{27}$

Child food insecurity has been identified in previous studies with African refugees. ${ }^{3,28}$ In the present study, $14.1 \%$ of participating households (10/71) reported reducing the portion size of their children's meals and that children had skipped meals because of financial constraints. This is indicative of food deprivation and hunger, a severe form of food insecurity. This finding is cause for concern because reduced food intake and disrupted eating patterns can compromise diet quality ${ }^{29}$ and impair children's social, health, and academic outcomes ${ }^{30}$ and is also linked to antisocial behavior. ${ }^{31}$ In the present study, there were more households that reported adult food insecurity compared to those that reported child food insecurity. This may be a result of the adults shielding their children from food insecurity. Adult food insecurity is associated with both nutritional and health problems. ${ }^{9,27}$ Food insecurity among resettled African refugees needs to be addressed to ensure that integration into their new country is not compromised by poor health. ${ }^{32}$

Low education was identified as a predictor of food insecurity consistent with findings from other studies. ${ }^{3,10}$ In addition, the majority of those with low education also had low English proficiency and were unemployed. Although employment status was not a predictor of food insecurity in the present study, many participants (67\%) were unemployed, which may relate to their low education and English proficiency levels. Among resettled refugees, low education status, lack of recognition of previous academic qualifications and work experience, and discrimination contributes to high unemployment rates. ${ }^{33,34}$ Although refugees in Australia receive 510 hours of free English classes, many refugees, especially mothers with inadequate childcare, are unable to attend all classes. ${ }^{35}$ Consequently, many have low English proficiency, which is a barrier to gaining employment. ${ }^{36}$

Although length of stay in Australia was not associated with food insecurity, the present study found that a majority of those who were food insecure had resided in Australia for 5 years or more. In addition, 56\% of those who were unemployed had lived in Australia for more than 5 years. This indicates that food insecurity can endure well beyond the initial settlement period, possibly due to entrenched socioeconomic constraints associated with unemployment. Those with social support were less likely to be food insecure, suggesting that their social networks may protect against food insecurity. Social networks increase refugees' access to emotional support, as well as material support such as money and food. ${ }^{21}$ Although the present study did 
not investigate who participants called on when in need, the present findings confirm similar studies showing that lack of social support is a risk factor for food insecurity. ${ }^{18,19}$

Contrary to a study among food insecure Somali refugees in the United States, ${ }^{10}$ no difference in vegetable intake between food secure and insecure participants was detected. A plausible explanation is that the continued consumption of traditional foods postresettlement. The vegetables in the FFQ included both traditional African vegetables and Australian vegetables. Food insecure African refugees have been found to consume their traditional and staple foods postresettlement. ${ }^{3}$ However, these foods are expensive, ${ }^{37}$ which may increase the risk of food insecurity, although further research is required.

The present study has several limitations. Due to the difficulty of accessing the population of interest, a nonprobability sampling method was used. These purposive and snowball sampling strategies may have resulted in a selection bias. Given the nature of the population, the sample size was small $(n=71)$ and was conducted among refugees from only 3 African countries. The present findings should therefore be generalized to other African refugees in similar settings with caution. In addition, the study design was cross-sectional; hence, causative pathways of associations could not be established.

\section{CONCLUSIONS}

Food insecurity is more prevalent among postresettlement African refugees compared to the general Australian population. The present study provides evidence that food insecurity is associated with education and social support and endures beyond initial resettlement. In Australia, the Humanitarian Settlement Strategy provides assistance to those on refugee visas for the first 6-12 months, after which they are expected to have attained selfsufficiency. ${ }^{38}$ It is therefore important for resettlement agencies to develop measures that assist refugees beyond this period, because some may not have attained self-sufficiency. Additionally, welfare payments provided for such vulnerable groups should take into consideration the increasing cost of living.

Education and training, language, employment, social support networks, and community engagement are all important for successful integration and settlement. ${ }^{32}$ Providing opportunities for resettled refugees to access such services may work toward alleviating food insecurity among this group. Because refugees are not a homogenous group, resettlement programs that are tailored to the needs of the diverse refugee groups may be more beneficial. 


\section{ACKNOWLEDGEMENTS}

The authors have no conflicts of interest. C.G. conceived the study collected and analyzed the data and wrote the first draft of this article, N.H., S.S., P.L., and S.T. provided substantial input. Each author read and approved the final article. A special thanks to the participants who allowed us to interview them because this study would not have been possible without their support.

\section{FUNDING}

This study was partly supported by funding from the Population and Social Health Research Program, Griffith Health Institute.

\section{ETHICAL APPROVAL}

Ethical approval for this study was granted by the Griffith University Human Research Ethics Committee.

\section{REFERENCES}

1. Food and Agriculture Organization. Coming to terms with terminology. Available at: http://www.fao.org/docrep/meeting/026/MD776E.pdf. Accessed November 25, 2013.

2. Gallegos D, Ellies P, Wright J. Still there's no food! Food insecurity in a refugee population in Perth, Western Australia. Nutr Diet. 2008; 65(1):78-83.

3. Hadley C, Sellen D. Food security and child hunger among recently resettled Liberian refugees and asylum seekers: a pilot study. J Immigr Minor Health. 2006; 8:369-375.

4. Himmelgreen DA, Pérez-Escamilla R, Segura-Millan S, et al. Food insecurity among low-income Hispanics in Hartford, Connecticut: implications for public health policy. Hum Organ. 2000; 59:334-342.

5. Manandhar M, Share M, Friel S, Walsh O, Hardy F. Food, Nutrition and Poverty Among Asylum-Seekers in Northern Ireland. Galway: National University of Ireland and Combat Poverty Agency. 2006. Working Paper 06/01.

6. Hadley C, Zodhiates A, Sellen DW. Acculturation, economics and food insecurity among refugees resettled in the USA: a case study of West African refugees. Public Health Nutr. 2007; 10:405-412.

7. Tilbury F, Rapley M. "There are orphans in Africa still looking for my hands": African women refugees and the sources of emotional distress. Health Sociol Rev. 2004; 13(1):54-64.

8. Rose D, Oliveira V. Nutrient intakes of individuals from food-insufficient households in the United States. Am J Public Health. 1997; 87:1956-1961. 
9. Kirkpatrick S, Tarasuk V. Food insecurity is associated with nutrient inadequacies among Canadian adults and adolescents. J Nutr. 2008; 138:604-612.

10. Dharod JM, Croom JE, Sady CG. Food insecurity: its relationship to dietary intake and body weight among Somali refugee women in the United States. J Nutr Educ Behav. 2013; 45(1):47-53.

11. Renzaho AMN, Burns C. Post-migration food habits of sub-Saharan African migrants in Victoria: a cross-sectional study. Nutr Diet. 2006; 63(2):91-102.

12. Palermo C, Robinson C, Robertson K, Hii S. Approaches for prioritising the nutritional needs of refugee communities. Aust J Prim Health. 2012; 18(1):11-16.

13. Wong KC, Coveney J, Ward P, et al. Availability, affordability and quality of a healthy food basket in Adelaide, South Australia. Nutr Diet. 2011; 68(1):8-14.

14. Harrison MS, Coyne T, Lee AJ, Leonard D. The increasing cost of the basic foods required to promote health in Queensland. Med J Aust. 2007; 186(1):9-14.

15. Ahluwalia IB, Dodds JM, Baligh M. Social support and coping behaviors of lowincome families experiencing food insufficiency in North Carolina. Health Educ Behav. 1998; 25:599-612.

16. Shumaker SA, Brownell A. Toward a theory of social support: closing conceptual gaps. J Soc Issues. 1984; 40(4):11-36.

17. Sheldon Cohen E, Underwood LG, Gottlieb BH. Social Support Measurement and Intervention: A Guide for Health and Social Scientists. Oxford, New York: Oxford University Press; 2000.

18. Locher JL, Ritchie CS, Roth DL, Baker PS, Bodner EV, Allman RM. Social isolation, support, and capital and nutritional risk in an older sample: ethnic and gender differences. Soc Sci Med. 2005; 60:747-761.

19. Vozoris NT, Tarasuk VS. Household food insufficiency is associated with poorer health. J Nutr. 2003; 133:120-126.

20. Schweitzer R, Melville F, Steel Z, Lacherez P. Trauma, post-migration living difficulties, and social support as predictors of psychological adjustment in resettled Sudanese refugees. Aust NZ J Psychiatry. 2006; 40(2):179-188.

21. McMichael C, Manderson L. Somali women and well-being: social networks and social capital among immigrant women in Australia. Hum Organ. 2004; 63(1):88-99.

22. Sulaiman-Hill C, Thompson S. Sampling challenges in a study examining refugee resettlement. BMC Int Health Hum Rights. 2011; 11(2):1-10.

23. Bickel G, Nord M, Price C, Hamilton W, Cook J. Guide to Measuring Household Food Security, Revised 2000. Available at: http://www.fns.usda.gov/fsec/files/ fsguide.pdf. Accessed September 25th, 2013.

24. Kersey M, Geppert J, Cutts DB. Hunger in young children of Mexican immigrant families. Public Health Nutr. 2007; 10:390-395.

25. Harrison GG, Stormer A, Herman DR, Winham DM. Development of a Spanishlanguage version of the US household food security survey module. J Nutr. 2003; 133:1192-1197.

26. Nolan M, Rikard-Bell G, Mohsin M, Williams M. Food insecurity in three socially disadvantaged localities in Sydney, Australia. Health Promot J Aust. 2006; $17: 247-254$. 
27. Ramsey R, Giskes K, Turrell G, Gallegos D. Food insecurity among adults residing in disadvantaged urban areas: potential health and dietary consequences. Public Health Nutr. 2012; 15:227-237.

28. Dharod JM, Croom JE. Child hunger: its prevalence and association with body mass index and dietary intake among Somali refugee children in the United States. NAPA Bull. 2010; 34(1):126-140.

29. Skalicky A, Meyers AF, Adams WG, Yang Z, Frank DA. Child food insecurity and iron deficiency anemia in low-income infants and toddlers in the United States. Matern Child Health J. 2006; 10(2):177-185.

30. Alaimo K, Olson CM, Frongillo EA Jr, Briefel RR. Food insufficiency, family income, and health in US preschool and school-aged children. Am J Public Health. 2001; 91:781-786.

31. Whitaker RC, Phillips SM, Orzol SM. Food insecurity and the risks of depression and anxiety in mothers and behavior problems in their preschool-aged children. Pediatrics. 2006; 118:e859-e868.

32. Ager A, Strang A. Understanding integration: a conceptual framework. J Refug Stud. 2008; 21(2):166-191.

33. Krahn H, Derwing T, Mulder M, Wilkinson L. Educated and underemployed: refugee integration into the Canadian labour market. J Int Migr Integr. 2000; 1(1):59-84.

34. Colic-Peisker V, Tilbury F. Integration into the Australian labour market: the experience of three "visibly different" groups of recently arrived refugees. Int Migr. 2007; 45:59-85.

35. Riggs E, Block K, Gibbs L, et al. Flexible models for learning English are needed for refugee mothers. Aust J Adult Learn. 2012; 52:397-405.

36. Pittaway E, Muli C, Shteir S. "I have a voice-hear me!" Findings of an Australian study examining the resettlement and integration experience of refugees and migrants from the Horn of Africa in Australia. Refuge: Canada's Journal on Refugees. 2009; 26(2):133-146.

37. Patil CL, McGown M, Nahayo PD, Hadley C. Forced migration: complexities in food and health for refugees resettled in the United States. NAPA Bull. 2010; 34:141-160.

38. Department of Immigration and Border Protection. Humanitarian Settlement Services. Available at: http://www.immi.gov.au/living-in-australia/deliveringassistance/government-programs/settlement-programs/hss.htm. Accessed September 1, 2013. 